\title{
Clinical Predictors of Diagnostic Testing Utility in the Initial Evaluation of Chronic Kidney Disease
}

\author{
Mallika L. Mendu, MD, MBA ${ }^{1}$, Andrew Lundquist, MD², Ayal A. Aizer, MD, MHS ${ }^{3}$, David E. \\ Leaf, MD, MMSc ${ }^{1}$, Emily Robinson, MD, MPH ${ }^{1}$, David J.R. Steele, MD ${ }^{2}$, and Sushrut S. \\ Waikar, MD, MPH ${ }^{1}$ \\ ${ }^{1}$ Division of Renal Medicine, Brigham and Women's Hospital, Harvard Medical School, Boston \\ MA \\ ${ }^{2}$ Nephrology Division, Massachusetts General Hospital, Harvard Medical School, Boston MA \\ ${ }^{3}$ Harvard Radiation Oncology Program, Boston MA
}

\section{Abstract}

Aim-No evidence-based approach to the evaluation of CKD has been established. We sought to identify clinical criteria to guide a rational diagnostic approach for the initial evaluation of CKD.

\begin{abstract}
Methods-We conducted a retrospective cohort study of 1,487 patients presenting for initial evaluation of CKD over three years (1/2010-1/2013) to academic nephrology clinics. We utilized the electronic medical record to determine tests ordered, abnormal results, and testing that affected diagnosis and/or management. Diagnostic and management yield of testing was defined as the percentage of tests that affected diagnosis and/or management. High yield for a given test was defined as an increased likelihood of the test affecting diagnosis and/or management.
\end{abstract}

Results-We identified clinical criteria predictive of high yield for paraprotein-related testing (one of the following: history of monoclonal disease, high risk of CKD progression, hypercalcemia or hemoglobin $<10.6$ ), and clinical criteria predictive of high yield for glomerulonephritis testing (one of the following: abnormal urine sediment, 3+ or greater hematuria or proteinuria $>500 \mathrm{mg} / \mathrm{gm}$ ). A prior history of hydronephrosis and renal artery stenosis was predictive of high yield of abnormal renal ultrasound. Higher yield of testing was associated with higher risk progression categories for ANA, SPEP, urine sediment, calcium, PTH, hemoglobin, iron, and ferritin. We estimate that initial CKD evaluation costs range from $\$ 28$ to \$109 million/year in US-Medicare expenditure.

Corresponding author: Mallika L. Mendu MD, MBA, Brigham and Women's Hospital, Division of Renal Medicine, 75 Francis Street, MRB-4, Boston, MA 02115, Telephone: 203.809.9190, Fax: 617.732.6392, mmendu@ partners.org.

Author Contributions: Drs. Mendu and Waikar take responsibility for the integrity of the data and the accuracy of the data analysis. Study concept and design: Mendu, Waikar

Acquisition of data: Mendu, Robinson

Analysis and interpretation of data: Mendu, Aizer, Waikar

Drafting of the manuscript: Mendu, Waikar, Steele, Robinson, Lundquist, Leaf

Critical revision of the manuscript for important intellectual content: Mendu, Waikar

Statistical analysis: Mendu, Aizer, Waikar

Administrative, technical, or material support: Waikar

Study supervision: Waikar

Competing Interests: All authors state that they have no competing interests. 
Conclusion-Numerous tests without significant clinical utility are obtained in initial CKD evaluation. Identifying criteria that can guide diagnostic testing may lead to a more informed and cost-effective approach to evaluation.

\section{Keywords}

Chronic Renal Insufficiency; Kidney Disease

\section{Background}

Chronic kidney disease (CKD) affects approximately $13 \%$ of adults in the United States (US), over $10 \%$ of the global population, and is associated with significant morbidity, mortality and healthcare costs. ${ }^{1-6}$ The incidence and prevalence of CKD have risen dramatically, partly due to the increasing prevalence of diabetes and hypertension. ${ }^{3}$ The differential diagnosis for CKD is broad and includes diabetes, hypertension, primary and secondary glomerulonephritis, tubulointerstital disease, vascular disease, urological causes and unknown. ${ }^{2}$ A number of laboratory and imaging tests are available to determine the etiology of CKD. Despite the pervasiveness and impact on healthcare costs, no evidencebased approach to evaluating CKD has been established.

Consensus-based recommendations exist from national and international organizations such as the Kidney Disease Improving Global Outcomes (KDIGO) $)^{7,8}$ and the Kidney Disease Outcomes Quality Initiative (KDOQI). ${ }^{2}$ KDIGO recommends evaluating "the clinical context" and obtaining a urinalysis, renal ultrasound, serum and urine electrolytes in most patients. ${ }^{7,8} \mathrm{KDOQI}$ recommends clinical clues to potential diagnoses to guide evaluation and recommends that all patients have a serum creatinine, urine protein, urine sediment or urine dipstick, renal ultrasound and serum electrolytes. ${ }^{2}$ Reviews aimed at primary care physicians (PCPs) outline a broad list of potential diagnoses and testing, without guidance regarding when to utilize certain tests. ${ }^{9}$

We recently found that numerous tests are ordered in the initial evaluation of CKD despite low diagnostic yield. ${ }^{10}$ The tests with the highest yield for diagnosis and/or management were hemoglobin A1c and urine protein quantification. Tests that had low yield included renal ultrasonography, testing for paraprotein-associated kidney disease, and serologic testing for glomerular diseases. To investigate these tests further and to clarify their role in the diagnostic evaluation of CKD, we sought to identify the factors associated with a higher yield, defined as testing that affected diagnosis and/or management. We developed a framework to guide providers regarding testing decisions in the initial evaluation of CKD. Finally, we also calculated the US-Medicare reimbursement costs associated with CKD evaluation testing.

\section{Methods}

\section{Study Design and Patient Population}

We identified patients referred (primarily by primary care providers within the same hospital network) for initial evaluation of CKD between January 1, 2010- January 1, 2013 to 
nephrology clinics affiliated with Brigham and Women's Hospital (BWH) and Massachusetts General Hospital (MGH) in Boston, MA. The institutional review board approved the study and waived the need for consent. Patients were excluded if evaluated for a second opinion, had another reason for referral (i.e. uncontrolled hypertension, hyperkalemia etc.), or were re-establishing care. Of 3,829 patients identified by the clinics' internal records of patient referrals, 1,487 patients were included in the final analysis.

\section{Data Sources and Collection}

The BWH/MGH Research Patient Data Registry and electronic medical record were utilized to abstract data from nephrology and primary care progress notes, laboratory and imaging results by author MM. We used methods recommended to ensure the validity and reliability of data collected, including a standardized abstraction database, precisely defined variables and criteria, and review by two authors (MM and SW) of ten initial charts to refine criteria. ${ }^{11}$ Data collected included demographics, visit dates, comorbidities, initial medications, blood pressures, labs, imaging, biopsies, need for renal replacement, and medication changes. We documented whether a test was obtained by another provider, such as a PCP or urologist, prior to the nephrology visit. All nephrology progress notes were manually reviewed to ascertain whether a test was documented to affect diagnosis and/or management, the presumed etiology of CKD and specific management decisions.

\section{Criteria for Diagnostic Testing}

Abnormal findings for labs were based on the reference range established by the BWH and MGH laboratories. An abnormal finding for imaging was defined as any abnormality reported in the final report, with the exception of simple cysts and non-obstructing stones for renal ultrasound. Tests were considered to have affected diagnosis if it was specifically stated in the nephrology progress notes to contribute to, confirm, or establish the underlying etiology of CKD. Tests were considered to have affected management if it was specifically stated in the nephrology progress notes to contribute to, confirm, or establish any management decision. These definitions included negative and positive test results and all diagnoses related to CKD. A blind abstraction of 36 random patients' records ( $2.4 \%$ of the total number of patients) was conducted by a second reviewer (author ER). Inter-rater agreement, assessed by the prevalence-adjusted, bias-adjusted kappa statistic, ${ }^{12,13}$ was mean of 0.89 (standard error of 0.015 ) for the diagnostic test variables.

\section{Clinical Utility}

We determined the frequency and yield of CKD diagnostic testing stratified by KDIGO 2012 risk categories (defined based on estimated glomerular filtration rate (eGFR) and albuminuria). ${ }^{7}$ Clinical criteria for the diagnostic/management yield of tests for paraproteinassociated kidney disease glomerular diseases [serum protein electrophoresis (SPEP), urine protein electrophoresis (UPEP), serum free light chains (FLC) and serologic tests such as antinuclear antibody (ANA), complement component 3 (C3), complement component 4 (C4), double stranded DNA (DsDNA), Anti-Ro Antibody (Ro), and Anti-La Antibody (La)] were identified based on clinical features associated with multiple myeloma and immunerelated kidney disease described in previous literature. ${ }^{14-16}$ 


\section{Statistical Methods}

Categorical variables were reported as percentages and compared using Fisher's exact test and the chi-square trend test as appropriate. Denominators were the number of tests obtained, and the numerators were the number of tests in which findings were abnormal or affected diagnosis and/or management. We determined clinical characteristics associated with certain tests (renal ultrasound, immunoglobulin-related testing, serologic testing) affecting diagnosis and management using Fisher's exact test. Chi-square trend tests were used to ascertain if there was an association between increasing KDIGO risk category and the frequency of testing obtained, rates of abnormal results, and diagnostic/management yield. For clinical predictors of renal ultrasound testing yield we calculated likelihood ratios and $95 \%$ confidence intervals. A two-sided $\mathrm{p}<0.05$ was considered statistically significant. Statistical analyses were performed using SAS version 9.3 software (SAS Institute, Cary, $\mathrm{NC})$.

\section{Cost Calculations}

We calculated cost using the Centers for Medicare fee schedule for outpatient services. ${ }^{17,18}$ The cost per test affecting diagnosis and/or management was calculated as the total cost associated with a given test in the study divided by the number of tests that affected diagnosis and/or management. The projected annual cost for the US population was calculated as the cost per test, multiplied by the frequency of the test ordered in this study, multiplied by the estimated annual incidence of CKD in patients younger than 80; this figure was 335, 961, based on Drey et al., which calculated an annual incidence rate of 1071 per million population and US census data from 2010 estimating a population of 313, 696, 890 younger than $80 .{ }^{19,20} \mathrm{We}$ excluded patients 80 and older assuming that providers would be less likely to pursue a workup. Finally, we estimated approximately $26 \%$ of CKD patients annually would be referred to nephrology based on published referral rates ${ }^{21}$ multiplying projected annual cost by $26 \%$ provided a low estimate of projected annual cost.

\section{Results}

\section{Clinical Characteristics}

Table 1 depicts characteristics of the 1,487 patients included in the study. The median age was 70 (IQR 61,79) years and $61.4 \%$ were male. The most common comorbidities included hypertension $(79.0 \%)$, diabetes $(58.4 \%)$, and coronary artery disease $(25.7 \%)$. The most common medications prescribed prior to the initial visit included statins (58.2\%), betablockers (54.5\%) and angiotensin-converting-enzyme inhibitors (40.9\%); 13.7\% were treated with nonsteroidal anti-inflammatory drugs (NSAIDs). The most frequent CKD stage was $3 \mathrm{~b}$ (39.6\%), followed by stage $3 \mathrm{a}(28.7 \%)$ and stage 4 (18.6\%). Three percent of the cohort progressed to CKD stage 5 requiring renal replacement therapy during the study period.

\section{Clinical Factors Associated with Higher Yield of Laboratory Tests}

We stratified the study population based on KDIGO risk categories as shown in Figure 1. ANA, C3, C4, cryoglobulins, SPEP, UPEP, FLC, HbA1c, calcium, phosphate, PTH, 25- 
vitamin $\mathrm{D}$, hemoglobin, iron and ferritin were more likely to be obtained with increasing risk category. Increasing yield of testing associated with increasing risk category was found with ANA, SPEP, urine sediment, calcium, PTH, hemoglobin, iron, and ferritin. We also evaluated two sets of clinical criteria, based on published literature, ${ }^{14-16}$ to identify tests that had high yield for the diagnosis of paraprotein-related kidney disease and glomerulonephritis (Table 2). The tests examined were SPEP, UPEP or FLC for paraproteinrelated kidney disease, and ANA, C3, C4, DsDNA, anti-Ro and anti-LA for glomerulonephritis. A high yield for paraprotein-related kidney disease was observed when any one of the following criteria were met: history of monoclonal disease, KDIGO risk stage 4 (based on eGFR and proteinuria), hypercalcemia (serum calcium >10.7) or anemia (hemoglobin < 10.6). These criteria identified 21 of 22 patients who had a positive SPEP, UPEP, or FLC that led to a diagnosis or management decision; one patient that did not meet either criteria was diagnosed with suspected IgA nephropathy based on mildly decreased $\operatorname{IgA}$. Of note, we also looked at laboratory criteria alone and found that all 21 patients met the following: either eGFR $<45 \mathrm{ml} / \mathrm{min} / 1.73 \mathrm{~m} 2$ or $>1$ gram of urine protein (on spot and/or 24 hour urine total protein or microalbumin). A high yield for glomerulonephritis testing was observed when any of the following clinical criteria were met: abnormal urine sediment (any finding other than an acellular sediment or epithelial cells), 3+ or greater hematuria or proteinuria $>500 \mathrm{mg}$ (per gm creatinine on spot and/or per day 24 hour urine total protein or microalbumin). All 11 patients who were diagnosed with glomerulonephritis had at least one of these laboratory abnormalities. The majority of patients who underwent glomerulonephritis laboratory testing (306 of 493) had none of these laboratory abnormalities, and none led to a diagnosis or management decision. Of note, ANCA and anti-GBM were not abnormal and did not affect diagnosis and/or management in any cases.

\section{Renal Ultrasound Testing Characteristics}

Results of renal ultrasound testing are shown in Table 3. The most common abnormal findings among the 1007 patient who had renal ultrasound were increased echogenicity (10.3\%), renal artery stenosis (4.3\%), and cortical thinning (4.3\%), and 59 led to a diagnosis (27 with hypertensive nephroslcerosis, 16 with renovascular related and 13 with hydronephrosis). Results of renal ultrasound led to a new and unsuspected diagnosis of polycystic kidney disease in one case. In 12 cases, the diagnosis of previously unsuspected obstructive uropathy was made (4 were severe, and 2 resulted in urologic intervention). The most common management decisions based on renal ultrasound were stopping or avoiding angiotensin-converting-enzyme inhibitors and angiotensin receptor blockers, blood pressure control, and urology referral/intervention. Higher yield was observed in patients with a history of hydronephrosis or renal artery stenosis $\left({ }^{+} \mathrm{LR} 12.7,{ }^{+} \mathrm{LR} 8.3\right.$, respectively, $\left.\mathrm{p}<.001\right)$; 7 of 65 who had a high yield ultrasound had a history of hydronephrosis (8 out of 942 patient who did not have a high yield ultrasound had a history of hydronephrosis), and 4 of 65 patients who had a high yield ultrasound had a history of renal artery stenosis ( 7 out of 942 patient who did not have a high yield ultrasound had a history of renal artery stenosis).

\section{Proposed Framework for CKD Evaluation}

Table 4 illustrates common examples of diagnoses and management decisions for testing obtained in evaluating CKD. For example, patients who had a LDH or haptoglobin affect 
diagnosis and/or management were diagnosed with tacrolimus related thrombotic microangiopathy and had tacrolimus discontinued. Based on the findings in this study, we have proposed a diagnostic framework for providers evaluating patients with CKD (Figure 2).

\section{Diagnoses and Management Decisions}

The most common etiologies documented as the presumed cause of CKD were hypertensive nephrosclerosis (41.2\%), diabetic kidney disease (26.8\%), and vascular disease (13.3\%). The diagnosis was listed as unknown in $16.4 \%$ (supplementary eTable 2). A total of 70 patients underwent kidney biopsy (supplementary eTable 1). The most common biopsy findings included secondary focal segmental glomerulosclerosis (41.4\%), arteriosclerosis (22.9\%) and diabetic nephropathy (22.9\%). The most commonly started medication were Vitamin D supplementation (8.7\%), ACE-I or ARB (6.6\%), and active vitamin D (6.0\%) (supplementary eTable 3). Management recommendations after initial evaluation of CKD included avoidance of NSAIDs (35.4\%), blood pressure control (30.7\%), and low sodium $\operatorname{diet}(11.2 \%)$ (supplementary eTable 4$)$.

\section{Cost Implications}

Supplementary eTable5 shows the cost in Medicare expenditure of testing in the initial evaluation of CKD. The cost per test that affected diagnosis and/or management ranged from $\$ 2677$ for renal ultrasound to $\$ 30$ for urine total protein to creatinine. We extrapolated our findings to the US population and found that the initial evaluation of CKD patients annually would be close to $\$ 109$ million if all patients who developed CKD were evaluated for the condition. We calculated a low estimate of annual cost of $\$ 28.0$ million, based on an estimation of CKD patients who would be referred to nephrology. Excluding the highest yield tests such as HbA1c and urine quantification studies, cost of CKD evaluation ranges from \$27 million to \$106 million; therefore, a more stringent approach to testing utilization for CKD evaluation could lead to significant cost savings.

\section{Discussion}

In this analysis of patients presenting for an initial evaluation of CKD, we have identified that certain clinical criteria — such as the presence of an abnormal urine sediment, hematuria or proteinuria for glomerulonephritis testing; the presence of monoclonal disease, KDIGO risk stage 4 , hypercalcemia or anemia for paraprotein testing — were associated with higher yield for testing related to paraprotein-associated kidney disease or glomerulonephritis. For renal ultrasound, having a prior history of hydronephrosis or a prior history of renal artery stenosis increased the likelihood of the test contributing to determining the etiology of CKD. We also calculated that the annual Medicare expenditure on CKD evaluation testing is close to $\$ 109$ million if all patients who develop the condition annually are evaluated. Notably, this figure does not include the cost of additional follow-up testing and monitoring (e.g., bone marrow biopsy in patients with an abnormal SPEP, repeating the renal ultrasound in patients with hydronephrosis, etc.). Finally, we have developed a framework based on our findings to guide providers evaluating patients with CKD. 
Few studies have examined testing related to CKD. A survey of 301 physicians, presented a hypothetical CKD patient, showed that $47 \%$ of nephrologists and $33 \%$ of internists could identify five of six tests indicated by KDOQI guidelines, ${ }^{22} 85 \%$ of physicians recommended at least 1 additional test (such as SPEP, uric acid, ANA), accounting for a $23 \%$ increase in per-patient cost. One study examined the utility of SPEP in 2544 patients being evaluated for CKD and found that $63.2 \%$ had the test obtained and no patient had the test affect diagnosis. ${ }^{23}$ Another study evaluated the role of SPEP and UPEP in 165 males with nephrotic range proteinuria, and myeloma was diagnosed with $1.2 \%$ of patients, with a cost per case of myeloma or MGUS of $\$ 1,192 .^{24}$

Our study raises a number of important issues related to diagnostic testing in CKD. First, most testing does not have high utility which can drive up healthcare costs. It may be that with the lack of an evidence-based approach to diagnostic evaluation, providers err on the side of being comprehensive when obtaining testing, but ordering tests increases physicians' time demands. Renal ultrasound was one of the most commonly ordered tests. The majority of abnormal findings were non-specific, such as increased echogenicity and cortical thinning, and most common diagnoses in patients whose ultrasounds affected diagnosis were hypertension and renovascular disease. However, there was 1 new diagnosis of polycystic kidney disease and 2 new diagnoses of severe hydronephrosis warranting urologic intervention. Though we were able to identify that a history of hydronephrosis and a history renal artery stenosis were predictors of a higher yield diagnostic renal ultrasound, further study in the form of a cost-effectiveness analysis may be warranted. We stratified the patient population based on KDIGO risk categories for CKD progression to determine if increasing risk category results in higher yield. While we found this to be the case for labs related to CKD management (hemoglobin, iron, ferritin, PTH) and certain diagnostic labs (urine sediment, SPEP, and $\mathrm{HbA1c}$ ) increased risk category was not associated with greater yield for most tests. Even for patients in the very high risk category, reflexively ordering a large number of tests may not be the optimal approach to CKD evaluation. For glomerular diseases or paraprotein-related diseases, relevant laboratory and clinical clues greatly increased the yield of diagnostic testing. The majority of patients in this study who underwent diagnostic testing for glomerulonephritis, for example, had neither an abnormal urine sediment or significant hematuria or proteinuria.

Our results suggest that the potential price tag for CKD testing in the US annually may be approximately $\$ 109$ million (compared to the annual allocation of the National Institutes of Health funds to kidney, urologic and hematologic research of $\$ 418$ million). ${ }^{25} \mathrm{CKD}$ evaluation, like in other areas of medicine, ${ }^{26,27}$ may represent an opportunity for cost savings through optimizing diagnostic testing strategies.

The major limitation of this study is the subjective nature of evaluating whether a test affected diagnosis or management, based on the interpretation of nephrology progress notes. We sought to address this by undertaking an initial review of 10 charts and ensuring that there was agreement by two of the authors, both nephrologists, of testing criteria. We also ensured that another nephrologist, not involved in the study design reviewed a subset of patient records, and we found significant agreement between reviewers based on the kappa statistic. Other limitations include the potential underestimation of diagnostic yield due to 
lack of documentation surrounding decision making, limited generalizability due to the inclusion of academic medical centers, and calculation of costs using Medicare charges not being reflective of the true cost of the testing to the hospital and not being generalizable to countries with low gross domestic product (GDP) compared to the United States. We provided a high and low estimate for national annual costs associated with CKD evaluation as it unclear how often patients who develop CKD undergo evaluation for the condition. Assuming all patients who develop CKD would obtain a diagnostic evaluation provides an overestimate. Assuming that only patients who are referred to nephrology will have diagnostic testing for the condition provides an underestimation of cost since tests be ordered again for monitoring, and some CKD evaluation may be done by PCPs without referral to nephrology clinics. Given the limited generalizability of our findings to countries with low GDP, we would propose additional investigations in diverse settings.

In conclusion, diagnostic testing in CKD is frequently of low-yield. We have identified clinical criteria that may guide diagnostic testing strategies, improve the yield and lower the costs of the initial evaluation of CKD.

\section{Supplementary Material}

Refer to Web version on PubMed Central for supplementary material.

\section{Acknowledgments}

Funding/Support: There was no external financial support for this study.

\section{References}

1. Coresh J, Selvin E, Stevens LA, et al. Prevalence of chronic kidney disease in the United States. JAMA. 2007 Nov 7; 298(17):2038-2047. [PubMed: 17986697]

2. K/DOQI clinical practice guidelines for chronic kidney disease: evaluation, classification, and stratification. Am J Kidney Dis. 2002 Feb; 39(2 Suppl 1):S1-S266. [PubMed: 11904577]

3. US Renal Data System: USRDS 2010 Annual Data Report. The National Institutes of Health, National Institutes of Diabetes and Digestive and Kidney Disease, Bethesda, MD. 2010 www.usrds.org/2010/pdf/v1_00a_intros.PDF.

4. US Department of Health and Human Services: Healthy People 2010. Washington, DC: US Government Printing Office; 2000.

5. Go AS, Chertow GM, Fan D, McCulloch CE, Hsu CY. Chronic kidney disease and the risks of death, cardiovascular events, and hospitalization. N Engl J Med. 2004 Sep; 351(13):1296-1305. [PubMed: 15385656]

6. Stenvinkel P. Chronic kidney disease: a public health priority and harbinger of premature cardiovascular disease. J Intern Med. 2010 Nov; 268(5):456-467. [PubMed: 20809922]

7. KDIGO 2012 Clinical Practice Guideline for the Evaluation and Management of Chronic Kidney Disease. http://www.kdigo.org/clinical_practice_guidelines/pdf/CKD/KDIGO_2012_CKD_GL.pdf.

8. Stevens PE, Levin A. Evaluation and management of chronic kidney disease: synopsis of the kidney disease: improving global outcomes 2012 clinical practice guideline. Ann Intern Med. 2013 Jun 4; 158(11):825-830. [PubMed: 23732715]

9. Baumgarten M, Gehr T. Chronic Kidney Disease: Detection and Evaluation. Am Fam Physician. 2011 Nov; 84(10):1138-1148. [PubMed: 22085668]

10. Mendu ML, Lundquist A, Aizer AA, et al. The Usefulness of Diagnostic Testing in the Initial Evaluation of Chronic Kidney Disease. JAMA Intern Med. 2015 Mar. 
11. Gilbert EH, Lowenstein SR, Koziol-McLain J, Barta DC, Steiner J. Chart reviews in emergency medicine research: Where are the methods? Ann Emerg Med. 1996 Mar; 27(3):305-308. [PubMed: 8599488]

12. Byrt T, Bishop J, Carlin JB. Bias, prevalence and kappa. J Clin Epidemiol. 1993 May; 46(5):423429. [PubMed: 8501467]

13. Van Ness PH, Towle VR, Juthani-Mehta M. Testing measurement reliability in older populations: methods for informed discrimination in instrument selection and application. J Aging Health. 2008; 20(2):183-197. [PubMed: 18089767]

14. Kyle RA, Gertz MA, Witzig TE, et al. Review of 1027 patients with newly diagnosed multiple myeloma. Mayo Clin Proc. 2003 Jan; 78(1):21-33. [PubMed: 12528874]

15. Cervera R, Khamashta MA, Font J, et al. Systemic lupus erythematosus: clinical and immunologic patterns of disease expression in a cohort of 1,000 patients. The European Working Party on Systemic Lupus Erythematosus. Medicine (Baltimore). 1993 Mar; 72(2):113-124. [PubMed: 8479324]

16. Kasitanon N, Magder LS, Petri M. Predictors of survival in systemic lupus erythematosus. Medicine (Baltimore). 2006 May; 85(3):147-156. [PubMed: 16721257]

17. http://www.cms.gov/Medicare/Medicare-Fee-for-ServicePayment/ClinicalLabFeeSched/ clinlab.html

18. http://www.cms.gov/Medicare/Medicare-Fee-for-Service-Payment/HospitalOutpatientPPS/ Hospital-Outpatient-Regulations-and-Notices-Items/CMS-1601-FC-.html

19. Drey N, Roderick P, Mullee M, Rogerson M. A population-based study of the incidence and outcomes of diagnosed chronic kidney disease. Am J Kidney Dis. 2003 Oct; 42(4):677-684. [PubMed: 14520617]

20. http://www.census.gov/2010census/

21. Allen AS, Forman JP, Orav EJ, Bates DW, Denker BM, Sequist TD. Primary care management of chronic kidney disease. J Gen Intern Med. 2011 Apr; 26(4):386-392. [PubMed: 20922494]

22. Charles RF, Powe NR, Jaar BG, Troll MU, Parekh RS, Boulware LE. Clinical testing patterns and cost implications of variation in the evaluation of CKD among US physicians. Am J Kidney Dis. 2009 Aug; 54(2):227-237. [PubMed: 19371991]

23. Doyle A, Soutar R, Geddes CC. Multiple myeloma in chronic kidney disease. Utility of discretionary screening using serum electrophoresis. Nephron Clin Pract. 2009; 111(1):c7-c11. [PubMed: 19033691]

24. Chew ST, Fitzwilliam J, Indridason OS, Kovalik EC. Role of urine and serum protein electrophoresis in evaluation of nephrotic-range proteinuria. Am J Kidney Dis. 1999 Jul; 34(1): 135-139. [PubMed: 10401027]

25. http://www.niddk.nih.gov/about-niddk/budget-legislative-information/Pages/budget-legislativeinformation.aspx

26. Wennberg JE. Unwarranted variations in healthcare delivery: implications for academic medical centres. BMJ. 2002 Oct 26; 325(7370):961-964. [PubMed: 12399352]

27. Wennberg JE, Fisher ES, Skinner JS, Bronner KK. Extending the P4P agenda, part 2: how Medicare can reduce waste and improve the care of the chronically ill. Health Aff (Millwood). 2007 Nov-Dec;26(6):1575-1585. [PubMed: 17978378] 


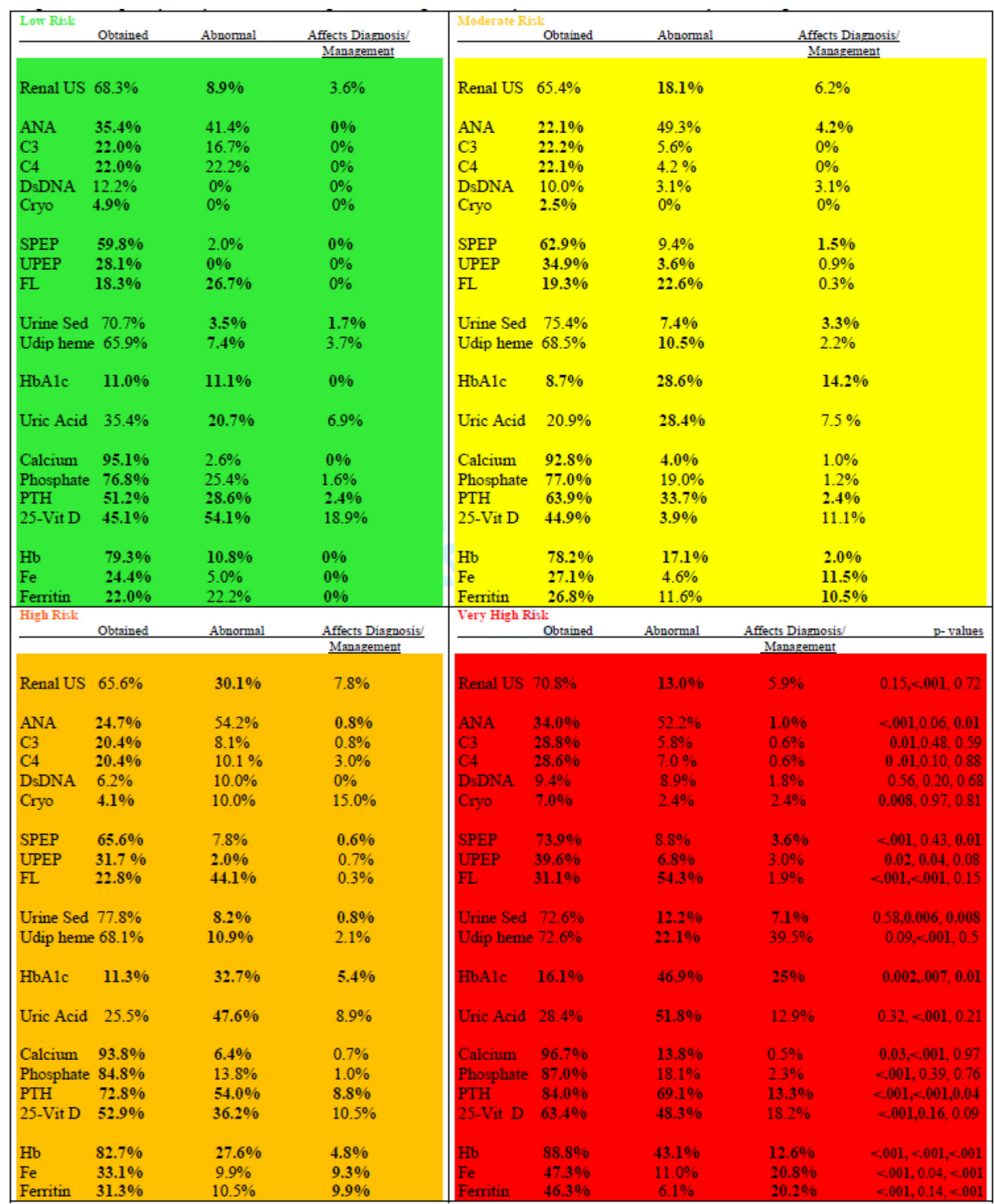

Figure 1. Frequency and yield of CKD diagnostic testing stratified by KDIGO 2012 stratified by risk categories

Abbreviations: CKD, chronic kidney disease; KDIGO, Kidney Disease Improving Global Outcomes; N, Number; \%, Percentage; Renal US, Renal ultrasound; ANA, antinuclear antibody; C3, complement component 3; C4, complement component 4; DsDNA, Double stranded DNA; Cryo, cryoglobulins; SPEP, serum protein electrophoresis; UPEP, urine protein electrophoresis; FL, serum free light chains; Urine sed, urine sediment; Udip heme, urine dipstick for blood; HbA1c, hemoglobin A1c; PTH, parathyroid hormone; Hb, hemoglobin; Fe, iron 
Bolded results indicate an association increasing risk category and frequency of testing obtained, abnormal and affecting diagnosis and/or management.

$\dagger$.Low Risk (Green)- GFR $>60 \mathrm{ml} / \mathrm{min} / 1.73 \mathrm{~m} 2$ and proteinuria $<30 \mathrm{mg} / \mathrm{g},<3 \mathrm{mg} / \mathrm{mmol}$ b.Moderate Risk (Yellow)- GFR $>60 \mathrm{ml} / \mathrm{min} / 1.73 \mathrm{~m} 2$ and proteinuria $30-300 \mathrm{mg} / \mathrm{g}, 3-$ $30 \mathrm{mg} / \mathrm{mmol}$, GFR $45-59 \mathrm{ml} / \mathrm{min} / 1.73 \mathrm{~m} 2$ and proteinuria $<30 \mathrm{mg} / \mathrm{g},<3 \mathrm{mg} / \mathrm{mmol}$ c. High Risk (Orange) GFR 30-44 ml/min/1.73 m2 and proteinuria $<30 \mathrm{mg} / \mathrm{g},<3 \mathrm{mg} / \mathrm{mmol}$, GFR $45-59 \mathrm{ml} / \mathrm{min} / 1.73 \mathrm{~m} 2$ and proteinuria $30-300 \mathrm{mg} / \mathrm{g}, 3-30 \mathrm{mg} / \mathrm{mmol}$, GFR $>60 \mathrm{ml} / \mathrm{min} /$ $1.73 \mathrm{~m} 2$ and proteinuria $>300 \mathrm{mg} / \mathrm{g},>30 \mathrm{mg} / \mathrm{nmol}$

d.Very High Risk (Red) GFR 0-29 ml/min/1.73 $\mathrm{m} 2$ and proteinuria $<30 \mathrm{mg} / \mathrm{g},<3 \mathrm{mg} / \mathrm{mmol}$, GFR $30-44 \mathrm{ml} / \mathrm{min} / 1.73 \mathrm{~m} 2$ and proteinuria $30-300 \mathrm{mg} / \mathrm{g}, 3-30 \mathrm{mg} / \mathrm{mmol}$, GFR $45-59$ $\mathrm{ml} / \mathrm{min} / 1.73 \mathrm{~m} 2$ and proteinuria $>300 \mathrm{mg} / \mathrm{g},>30 \mathrm{mg} / \mathrm{nmol}$

e. The denominator for the percentages provided is the number of patients in the risk category (low risk- denominator equals 82 , moderate risk- denominator equals 321 , high risk- denominator equals 486, very high risk- denominator equals 598).

$\mathrm{f}$. The denominator for the percentages provided is the number of tests obtained.

g. The denominator for the percentages provided is the number of tests obtained. 
Suggestions for diagnostic evaluation in patients initially presenting for $\mathrm{CKD}$ workup:

- Obtain urinalysis, urine sediment, spot urine protein quantification testing (urine microalbumin to creatinine ratio or urine protein to creatinine ratio) and $\mathrm{HbAlc}$ if history of diabetes or clinical suspicion of diabetes.

- Obtain renal ultrasound, particularly if there is any prior history of hydronephrosis or prior history of renal artery stenosis.

- Obtain paraprotein testing including SPEP, UPEP, FL if the patient meets one of the following: established monoclonal disease, KDIGO Risk stage $4,{ }^{a}$ Hypercalcemia, ${ }^{\text {b }}$ Anemia.

- Obtain serologic testing including ANA, C3, C4, DsDNA, Ro, La if the patient meets one of the following: abnormal urine sediment, $3+$ or greater hematuria or proteinuria. Consider testing with ANCA, Anti-GBM based on clinical context.

- Consider additional testing with $\mathrm{HBV}, \mathrm{HCV}, \mathrm{Cryoglobulins}$ based on clinical context (history of drug use, abnormal liver function, arthralgias, rash)

- Consider additional testing with haptoglobin, LDH based on clinical context (history of medications such as tacrolimus that can cause thrombotic microangiopathy)

- Consider additional testing with renal nuclear scan or abdominal CT based on clinical context (suspicion for renal artery stenosis, atrophic kidney, obstruction).

Figure 2. Proposed Framework for the Initial Diagnostic Evaluation of Chronic Kidney Disease Abbreviations: N, Number; \%, Percentage; SPEP, serum protein electrophoresis; UPEP, urine protein electrophoresis; ANA, antinuclear antibody; C3, complement component 3; $\mathrm{C} 4$, complement component 4; HCV, hepatitis C testing; HBV, hepatitis B testing; ANCA, Anti-neutrophil cytoplasmic antibody; LDL, Low-density lipoprotein; DsDNA, Double stranded DNA; Anti-GBM, Anti-Glomerular basement membrane antibody; Abdominal CT, Abdominal computed topography; LDH, lactate dehydrogenase; MRI, magnetic resonance imaging; MRA, magnetic resonance angiogram; N/A, not applicable

a. KDIGO risk stage 4 (very high risk) GFR 0-29 ml/min $/ 1.73 \mathrm{~m} 2$ and proteinuria <30 $\mathrm{mg} / \mathrm{g},<3 \mathrm{mg} / \mathrm{mmol}$, GFR 30-44 ml/min/1.73 m2 and proteinuria 30-300mg/g, 3-30mg/ $\mathrm{mmol}$, GFR $45-59 \mathrm{ml} / \mathrm{min} / 1.73 \mathrm{~m} 2$ and proteinuria $>300 \mathrm{mg} / \mathrm{g},>30 \mathrm{mg} / \mathrm{nmol}$

b. Hypercalcemia- defined as a serum calcium greater than 10.7

c. Anemia-defined as a hemoglobin less than 10.6 


\section{Table 1}

Patient demographics and clinical characteristics

\begin{tabular}{|c|c|}
\hline Patient Characteristics & $\mathbf{N}(\%)$ \\
\hline Male & $914(61.4)$ \\
\hline Age, median (IQR) & $70(61,79)$ \\
\hline Married or with Partner & $845(56.8)$ \\
\hline English speaking & $1402(94.3)$ \\
\hline \multicolumn{2}{|l|}{ Race } \\
\hline White & $1084(72.9)$ \\
\hline African American & $189(12.7)$ \\
\hline Hispanic & $149(10.0)$ \\
\hline \multicolumn{2}{|l|}{ Comorbidities } \\
\hline Hypertension & $1175(79.0)$ \\
\hline Diabetes & $868(58.4)$ \\
\hline Coronary artery disease & $382(25.7)$ \\
\hline History of malignancy & $359(24.1)$ \\
\hline Gout & $207(13.9)$ \\
\hline Anemia & $182(12.2)$ \\
\hline Obesity & $164(11.0)$ \\
\hline Congestive heart failure & $142(9.6)$ \\
\hline Benign prostatic hypertrophy & $139(9.4)$ \\
\hline Kidney stones & $130(8.7)$ \\
\hline Connective tissue disease & $60(3.4)$ \\
\hline Nephrectomy & $44(3.0)$ \\
\hline Monoclonal disease & $41(2.8)$ \\
\hline Lupus & $18(1.2)$ \\
\hline History of hydronephrosis & $18(1.2)$ \\
\hline History of renal artery stenosis & $13(0.9)$ \\
\hline \multicolumn{2}{|l|}{ CKD Stage $^{\dagger}$} \\
\hline CKD Stage $1-2$ & $183(12.3)$ \\
\hline CKD Stage $3 \mathrm{a}$ & $427(28.7)$ \\
\hline CKD Stage $3 b$ & $589(39.6)$ \\
\hline CKD Stage 4 & $276(18.6)$ \\
\hline CKD Stage 5 & $12(0.8)$ \\
\hline \multicolumn{2}{|l|}{ Medications prior to initial visit } \\
\hline Statins & $865(58.2)$ \\
\hline Beta-blockers & $810(54.5)$ \\
\hline Angiotensin-converting-enzyme inhibitors & $608(40.9)$ \\
\hline Calcium channel blockers & $531(35.7)$ \\
\hline
\end{tabular}

Nephrology (Carlton). Author manuscript; available in PMC 2017 January 01. 


\begin{tabular}{|c|c|}
\hline Patient Characteristics & N (\%) \\
\hline Proton pump inhibitors & $426(28.7)$ \\
\hline Thiazides & $378(25.4)$ \\
\hline Loop diuretics & $307(20.7)$ \\
\hline Angiotensin receptor blockers & $306(20.6)$ \\
\hline Vitamin D supplementation & $245(16.5)$ \\
\hline Nonsteroidal anti-inflammatory drugs & $203(13.7)$ \\
\hline Allopurinol & $147(9.9)$ \\
\hline Required renal replacement therapy during study period \\
\hline Dialysis & $40(2.7)$ \\
\hline Transplant & $4(0.3)$ \\
\hline
\end{tabular}

Values represent $\mathrm{N}(\%)$ unless otherwise stated.

Abbreviations: CKD, Chronic Kidney Disease

${ }^{\dagger}$ Based on most recent estimated glomerular filtration (eGFR) rate prior to study enrollment period

CKD stage $1-2$ eGFR $>60 \mathrm{ml} / \mathrm{min}$ per $1.73 \mathrm{~m}^{2}$, stage $3 \mathrm{a}$ eGFR $45-59 \mathrm{ml} / \mathrm{min}$ per $1.73 \mathrm{~m}^{2}$, stage $3 \mathrm{~b}$ eGFR $30-44 \mathrm{ml} / \mathrm{min}^{\mathrm{per}} 1.73 \mathrm{~m}^{2}$, stage 4 eGFR $15-29 \mathrm{ml} / \mathrm{min}$ per $1.73 \mathrm{~m}^{2}$, stage $5 \mathrm{GFR}<15 \mathrm{ml} / \mathrm{min}$ per $1.73 \mathrm{~m}^{2}$ 
Table 2

Clinical criteria associated with higher yield of diagnostic testing

\begin{tabular}{|c|c|c|c|}
\hline $\begin{array}{l}\text { N=1035 (obtained SPEP, UPEP or } \\
\underline{F L C} \text { ) }\end{array}$ & 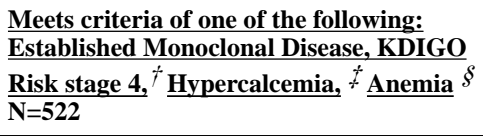 & $\begin{array}{l}\text { Does Not Meet } \\
\underline{\text { Criteria } N=513}\end{array}$ & $\underline{P \text {-value }}$ \\
\hline $\begin{array}{l}\text { SPEP or UPEP or FL } \\
\text { affects diagnosis or management }\end{array}$ & $21(4.0 \%)$ & $1(0.2 \%)$ & \multirow{2}{*}{0.004} \\
\hline $\begin{array}{l}\text { SPEP or UPEP or FL } \\
\text { does not affect diagnosis or } \\
\text { management }\end{array}$ & $501(96.0 \%)$ & $512(99.8 \%)$ & \\
\hline $\begin{array}{l}\text { N=493 (obtained ANA, C3, C4, } \\
\text { DsDNA, Ro, La) }\end{array}$ & $\begin{array}{l}\text { Meets criteria of abnormal urine } \\
\text { sediment, } / / 3+\text { or greater hematuria or } \\
\text { proteinuria }>500 \mathrm{mg} / \mathrm{gm} N=187\end{array}$ & $\begin{array}{l}\text { Does Not Meet } \\
\text { Criteria N= 306 }\end{array}$ & $\underline{\text { P-value }}$ \\
\hline $\begin{array}{l}\text { ANA/C3/C4/DsDNA/Ro/La affects } \\
\text { diagnosis or management }\end{array}$ & $11(5.9 \%)$ & $0(0 \%)$ & \multirow{2}{*}{$<0.001$} \\
\hline $\begin{array}{l}\text { ANA/C3/C4/DsDNA/Ro/La does not } \\
\text { affect diagnosis or management }\end{array}$ & $176(94.1 \%)$ & $306(100 \%)$ & \\
\hline
\end{tabular}

Abbreviations: SPEP, serum protein electrophoresis; UPEP, urine protein electrophoresis; FL, serum free light chains; ANA, antinuclear antibody; C3, complement component 3; C4, complement component 4; DsDNA, Double stranded DNA; Ro, Anti-Ro Antibody; La, Anti-La Antibody

${ }^{\dagger}$. KDIGO risk stage 4 (very high risk) GFR 0-29 ml/min/1.73 m2 and proteinuria $<30 \mathrm{mg} / \mathrm{g},<3 \mathrm{mg} / \mathrm{mmol}, \mathrm{GFR} 30-44 \mathrm{ml} / \mathrm{min} / 1.73 \mathrm{~m} 2$ and proteinuria $30-300 \mathrm{mg} / \mathrm{g}, 3-30 \mathrm{mg} / \mathrm{mmol}$, GFR $45-59 \mathrm{ml} / \mathrm{min} / 1.73 \mathrm{~m} 2$ and proteinuria $>300 \mathrm{mg} / \mathrm{g},>30 \mathrm{mg} / \mathrm{nmol}$

. Hypercalcemia- defined as a serum calcium greater than 10.7

$\S$. Anemia-defined as a hemoglobin less than 10.6

II. Any finding other than an acellular sediment or epithelial cells 


\section{Table 3}

\section{Renal Ultrasound Characteristics}

\begin{tabular}{|c|c|c|}
\hline Renal Ultrasound Characteristics & $\mathbf{N}$ & $\%$ \\
\hline Obtained & 1007 & $67.7 \%$ \\
\hline Ordered by Nephrology & $711 / 1007$ & $70.6 \%$ \\
\hline$\underline{\text { Abnormal Findings }}^{\dagger}$ & $270 / 1007$ & $26.8 \%$ \\
\hline Increased Echogenicity & $104 / 1007$ & $10.3 \%$ \\
\hline Stenosis & $43 / 1007$ & $4.3 \%$ \\
\hline Cortical Thinning & $43 / 1007$ & $4.3 \%$ \\
\hline Atrophy & $27 / 1007$ & $2.7 \%$ \\
\hline Hydronephrosis & $19 / 1007$ & $1.89 \%$ \\
\hline Evidence of Lithium disease & $2 / 1007$ & $0.2 \%$ \\
\hline Affected Diagnosis & $59 / 1007$ & $5.9 \%$ \\
\hline Hypertension-related diagnosis & \multicolumn{2}{|l|}{$27 / 1007$} \\
\hline Renovascular-related diagnosis & \multicolumn{2}{|l|}{$16 / 1007$} \\
\hline Hydronephrosis/Obstruction & \multicolumn{2}{|l|}{$13 / 1007$} \\
\hline $\begin{array}{r}\text { Atrophic/asymmetric/single } \\
\text { kidney }\end{array}$ & \multicolumn{2}{|l|}{$6 / 1007$} \\
\hline Renal artery stenosis & \multicolumn{2}{|l|}{$4 / 1007$} \\
\hline Lithium use & \multicolumn{2}{|l|}{$3 / 1007$} \\
\hline Polycystic kidney disease & \multicolumn{2}{|l|}{$1 / 1007$} \\
\hline Affected Management & $33 / 1007$ & $3.3 \%$ \\
\hline Stop/Avoid ACE-I or ARB & \multicolumn{2}{|l|}{$11 / 33$} \\
\hline Blood pressure control & \multicolumn{2}{|l|}{$9 / 33$} \\
\hline Urology referral/intervention & \multicolumn{2}{|l|}{$5 / 33$} \\
\hline \multicolumn{3}{|l|}{ Kidney Size } \\
\hline Right Kidney & \multicolumn{2}{|c|}{ Median $10.3 \mathrm{~cm}(9.4,11.2)$ Mean $9.7 \mathrm{~cm}$} \\
\hline Left Kidney & \multicolumn{2}{|c|}{ Median $10.4 \mathrm{~cm}(9.3,11.3)$ Mean $9.6 \mathrm{~cm}$} \\
\hline \multicolumn{3}{|c|}{ Predictors of Renal Ultrasound Affecting Diagnosis and/or Management } \\
\hline Prior history of Hydronephrosis & \multicolumn{2}{|c|}{${ }^{+} \mathrm{LR}=12.7(4.8,33.9) ;{ }^{-} \mathrm{LR}=0.9(0.8,1.0)$} \\
\hline Prior history of Renal Artery Stenosis & \multicolumn{2}{|c|}{${ }^{+} \mathrm{LR}=8.3(2.5,27.6) ;{ }^{-} \mathrm{LR}=1.0(0.9,1.0)$} \\
\hline
\end{tabular}

Abbreviations: N, Number; \%, Percentage; ACE-I, angiotensin converting enzyme-inhibitor; ARB, angiotensin receptor blocker;

${ }^{+}$LR, positive likelihood ratio, ${ }^{-}$LR, negative likelihood ratio, and $95 \%$ confidence interval presented

${ }^{\dagger}$. An abnormal finding for imaging was defined as any abnormality reported in the final report, with the exception of simple cysts and nonobstructing stones 


\section{Table 4}

Examples of diagnoses and management decisions for testing obtained in evaluating CKD

\begin{tabular}{|c|c|c|}
\hline Test Obtained & Diagnoses ${ }^{\dagger}$ & Management Decisions $*$ \\
\hline \multicolumn{3}{|c|}{ Tests primarily ordered for diagnosis } \\
\hline Urine sediment & $\begin{array}{l}\text { Acute interstitial nephritis due to proton pump } \\
\text { inhibitor (based on white blood cells) }\end{array}$ & Discontinuation of proton pump inhibitor \\
\hline Urine dipstick for protein & Likely diabetic nephropathy & Quantification of urine protein, started ACE-I \\
\hline Urine dipstick for blood & Lupus nephritis & Started on MMF and prednisone \\
\hline SPEP & Likely myeloma involving kidney & Referred to oncology for bone marrow biopsy \\
\hline Renal ultrasound & See supplementary eTable 2 & See supplementary eTable 2 \\
\hline Urine microalbumin to creatinine & Diabetic nephropathy & Started ACE-I, counseled diabetic control \\
\hline Urine total protein/creatinine & $\begin{array}{l}\text { Diabetic nephropathy versus secondary FSGS } \\
\text { due to obesity }\end{array}$ & Started ACE-I, counseled regarding weight loss \\
\hline UPEP & Light chain deposition disease & Referred to oncology, started on chemotherapy \\
\hline ANA & Lupus nephritis & Started on MMF and prednisone \\
\hline Uric Acid & Hyperuricemia contributing & Started on allopurinol \\
\hline Serum free light chains & Light chain deposition disease & Referred to oncology, started on chemotherapy \\
\hline $\mathrm{C} 3$ & Lupus nephritis & Started on MMF and prednisone \\
\hline $\mathrm{C} 4$ & Lupus nephritis & Started on MMF and prednisone \\
\hline $\mathrm{HBV}$ & $\begin{array}{l}\text { Hepatitis B unlikely contributing given absence } \\
\text { of proteinuria and low levels of hepatitis B }\end{array}$ & None \\
\hline $\mathrm{HCV}$ & Possible hepatitis C related MPGN & $\begin{array}{l}\text { Referral to hepatology for anti-viral treatment of } \\
\text { hepatitis C }\end{array}$ \\
\hline ANCA & N/A & N/A \\
\hline Hemoglobin A1c & Uncontrolled diabetic nephropathy & Counseled diabetic control, dietary modification \\
\hline Rheumatoid factor & Possible hepatitis C related MPGN & $\begin{array}{l}\text { Referral to hepatology for anti-viral treatment of } \\
\text { hepatitis C }\end{array}$ \\
\hline DsDNA & Lupus nephritis & Started on MMF and prednisone \\
\hline Anti-Ro & Lupus nephritis & Started on MMF and prednisone \\
\hline Anti-La & Lupus nephritis & Started on MMF and prednisone \\
\hline Cryoglobulins & Possible hepatitis C related cryoglobulinemia & Started on anti-viral treatment for $\mathrm{HCV}$ \\
\hline Ultrasound guided renal biopsy & See Table 3 & ACE-I treatment \\
\hline Anti-GBM & N/A & N/A \\
\hline Abdominal CT & Obstruction related & Urology referral for intervention \\
\hline Creatine Kinase & Possible rhabdomyolysis from statin & Stopped statin \\
\hline Renal nuclear scan & Renal artery stenosis & Avoid ACE-I or ARB \\
\hline LDH & Tacrolimus related TMA & Stopped tacrolimus \\
\hline Haptoglobin & Tacrolimus related TMA & Stopped tacrolimus \\
\hline Anti-phospholipid Antibody & FSGS related to anti-phospholipid antibody & Continued warfarin indefinitely \\
\hline HIV & N/A & N/A \\
\hline Abdominal MRI & N/A & N/A \\
\hline Abdominal MRA & N/A & N/A \\
\hline
\end{tabular}

Nephrology (Carlton). Author manuscript; available in PMC 2017 January 01. 


\begin{tabular}{|c|l|l|}
\hline \multicolumn{2}{|c|}{ Test Obtained } & \multicolumn{2}{|c|}{ Management Decisions ${ }^{\dagger}$} \\
\hline Tests primarily ordered for management & Held calcium supplementation \\
\hline Calcium & Possible hypercalcemia contributing & Started iron and/or ESA \\
\hline Hemoglobin & N/A & Started phosphate binder \\
\hline Phosphate & Tenofovir related (resulted in stopping tenofovir) & Started calcitriol \\
\hline Parathyroid hormone & N/A & Started ergocalciferol or cholecalciferol \\
\hline 25-Vitamin D & N/A & Started oral iron \\
\hline Iron & N/A & Started statin \\
\hline LDL & N/A & \\
\hline
\end{tabular}

Abbreviations: N, Number; \%, Percentage; SPEP, serum protein electrophoresis; UPEP, urine protein electrophoresis; ANA, antinuclear antibody; $\mathrm{C} 3$, complement component 3; C4, complement component 4; $\mathrm{HCV}$, hepatitis $\mathrm{C}$ testing; $\mathrm{HBV}$, hepatitis B testing; ANCA, Anti-neutrophil cytoplasmic antibody; LDL, Low-density lipoprotein; DsDNA, Double stranded DNA; Anti-GBM, Anti-Glomerular basement membrane antibody; Abdominal CT, Abdominal computed topography; LDH, lactate dehydrogenase; MRI, magnetic resonance imaging; MRA, magnetic resonance angiogram; ACE-I, angiotensin-converting-enzyme inhibitor; ARB, angiotensin receptor blocker; MMF, mycophenolate mofetil; FSGS, Focal segmental glomerulosclerosis; MPGN, membranoproliferative glomerulonephritis; TMA, thrombotic microangiopathy; ESA, erythropoiesis stimulating agent

${ }^{\dagger}$. Diagnoses represent most common diagnoses provided for a specific test that affected diagnosis; "Affected diagnosis" was defined as any test result that were noted in the nephrology progress notes to have contributed to, confirmed or established any diagnosis

*. Management decisions represent most common management decisions provided for a specific test that affected management; "Affected management" was defined as any test result that were noted in the nephrology progress notes to have contributed to any management decision 